\section{AB0991 OSTEOPOROSIS AND FRACTURES IN PATIENTS WITH CIRRHOSIS. CAN FRAX BE USEFUL FOR SCREENING?}

E. Casado ${ }^{1}$, M. Arévalo ${ }^{1}$, J. Profitós ${ }^{2}$, A. Lira ${ }^{3}$, L. Del Río ${ }^{4}$, O. Valero ${ }^{5}$, M. Larrosa ${ }^{1}$ J. Sánchez-Delgado ${ }^{3}$, J. Gratacós ${ }^{1}{ }^{1}{ }^{1}$ Rheumatology, University Hospital Parc Taulí. I3PT. UAB. Sabadell, Sabadell; ${ }^{2}$ Gastroenterology and Hepatology, Consorci hospitalari de Terrassa, Terrassa; ${ }^{3}$ Gastroenterology and Hepatology, University Hospital Parc Taulí. I3PT. UAB. Sabadell, Sabadell; ${ }^{4}$ Radiolgy, CETIR Centre Mèdic, Barcelona; ${ }^{5}$ Statistics, Universitat Autònoma Barcelona (UAB), Bellaterra, Spain

Background: Osteoporotic fractures are a serious complication in patients with cirrhosis. In addition to the high morbidity and mortality of the patients who suffer them, fragility fractures represent a high cost for Healthcare systems.

However, there are very few studies that evaluate the prevalence of osteoporosis and fractures in patients with liver cirrhosis different than primary biliary cirrhosis (non-PBC cirrhosis). There are also no clinical guidelines with recommendations for osteoporosis screening in these patients.

Objectives: To assess the prevalence of osteoporosis and fragility fractures in patients with non-PBC cirrhosis in our environment, and the associated risk factors.

To analyse if the FRAX tool can be useful in the diagnostic screening of these patients.

Methods: From November 2015 to September 2017, outpatients older than 40 years diagnosed with non-PBC cirrhosis (any Child stage) were randomly included.

Demographic, clinical and analytical data (calcium, phosphorus, 25-hydroxyvitamin D and PTH) were collected from all patients. A bone densitometry, GE, Lunar Prodigy (DXA) and vertebral fracture assessment (VFA) were also performed, for the diagnosis of osteoporosis ( $\mathrm{T}$-score $\leq-2.5$ ), and vertebral fracture. The 10 year absolute fracture risk was calculated using FRAX (https://www.sheffield. ac.uk/FRAX/tool.aspx?country=4)

A descriptive statistic of the main variables was carried out, with univariate and multivariate analysis to assess which predictive factors could be related to the presence of osteoporosis and/or fragility fractures.

Results: Ninety-two patients were included (71\% male and 29\% female). Age 63 \pm 11 years. The etiology of cirrhosis was: alcohol $(52 \%)$, hepatitis $C$ virus $(27 \%)$ and alcohol thepatitis C virus (9\%). Stage: Child A (80.4\%), B (17.4\%) and C (2.2\%). Mean 25-hydroxyvitamin D was $18.5 \pm 9.8 \mathrm{ng} / \mathrm{ml}$ and PTH $51.8 \pm 23.0 \mathrm{pg} /$ $\mathrm{ml}$.

16 patients (17\%) had osteoporosis by DXA, 54 patients $(59 \%)$ osteopenia and 22 $(24 \%)$ had a normal bone mineral density (BMD). 8 patients $(9 \%)$ had suffered some fragility fracture (vertebral fracture in 6 cases).

The 10 year absolute risk for major fracture (vertebra, humerus, femur or radius) by FRAX without BMD was $5.7 \pm 4.5$; and with BMD $4.7+4.9$.

Age and female sex were associated with the presence of osteoporosis, and a $\mathrm{BMI}$ higher than 30 was found to be a protective factor. A BMD in the range of osteoporosis was the only factor associated with fracture.

FRAX for major fracture without BMD higher than $6.6 \%$ in this population had a high sensitivity $(69 \%)$ and specificity $(85 \%)$ for the diagnosis of osteoporosis, which implies a negative predictive value of $93 \%$. Using this FRAX cut-off for indicating DXA in cirrhotic patients could expect a saving of $76 \%$ of DXA scans.

Conclusions: The prevalence of osteoporosis and fractures in patients with nonPBC cirrhosis, even in mild stages, is higher than in the healthy population, being more frequent in women and older patients.

The FRAX tool can be useful in the selection of patients with cirrhosis to be assessed by a bone densitometry.

Disclosure of Interest: None declared

DOI: 10.1136/annrheumdis-2018-eular.4072

\section{AB0992 1 BONE REMODELLING BIOMARKERS IN HIV INFECTED PATIENTS}

F. López ${ }^{1}$, J. Loarce ${ }^{1}$, C. Sobrino ${ }^{1}$, J.L. Casado ${ }^{2}$, M. Vázquez ${ }^{1} .{ }^{1}$ Rheumatology Department, ${ }^{2}$ Infectious Diseases Department, Ramon y Cajal University Hospital, Madrid, Spain

Background: Bone metabolism is an equilibrium of resorption and growth, maintained by many regulating factors. Several molecules have been identified that estimate bone turnover, being P1NP and b-CTX the most commonly used. Many studies have shown a relationship between their levels and metabolic bone disease, and possibly with risk of fracture.

Human Immunodeficiency Virus (HIV) infected patients have lower bone mineral density (BMD), as documented on many studies. An increased incidence of fractures has been noted as well, probably due to predisposing factors related to HIV infection, apart from the traditional risk factors.

Objectives: To assess the relationship between mean values of bone biomarkers P1NP and b-CTX and incidence of vertebral fractures (VF) in a HIV infected population; and compare such values with those of a Spanish healthy population of reference.

Methods: We performed a cross-sectional study with HIV infected patients followed up in the Infectious Diseases Department of our centre from 2014 to 2016 P1NP and $b-C T X$ values were determined and lumbar and thoracic spine radiographs made to assess presence of VF (Genant grading scale). Other clinical and demographic data were collected retrospectively. P1NP and b-CTX values in the presence (VF group) and absence of fractures (non-FV group) were compared. Mean values were also compared with the Camargo cohort, comprised of 1080 healthy postmenopausal Spanish women, used as reference. Statistical analysis were made with STATA. All patients signed and informed consent, previously approved by the Hospital's Ethics Comittee.

Results: A total of 144 patients were included, 38 were women with a mean age of 56,4 years old ${ }^{45-77}$ and 106 men with mean age of 56,5 years old. ${ }^{4-86} 27$ of the patients had at least one VF. No statistically significant differences were found between P1NP mean levels in the FV and the non FV groups, with values of $45,30 \mathrm{ng} / \mathrm{ml} \quad( \pm 17,59 \mathrm{ng} / \mathrm{ml})$ and $49.48 \mathrm{ng} / \mathrm{ml} \quad( \pm 32,92 \mathrm{ng} / \mathrm{ml})$ respectively, $(\mathrm{p}=0.52)$. Mean levels of $\mathrm{b}-\mathrm{CTX}$ were $0,38 \mathrm{ng} / \mathrm{ml}( \pm 0,18 \mathrm{ng} / \mathrm{ml})$ in the VF group and $0,43 \mathrm{ng} / \mathrm{ml}( \pm 0,22 \mathrm{ng} / \mathrm{ml})$ in the non-FV group, again without significant differences $(p=0,35)$.

Mean general b-CTX values in our population were $0,41 \mathrm{ng} / \mathrm{ml}( \pm 0,21) ; 0,46 \mathrm{ng}$ $\mathrm{ml}( \pm 0,20)$ in women and $0,39 \mathrm{ng} / \mathrm{ml}( \pm 0,20)$ in men. Higher levels were found in HIV infected women than in the Camargo cohort $(0,38 \pm 0,19 \mathrm{ng} / \mathrm{ml})$, with statistical significance $(p=0.03)$. Mean general P1NP values were $48.34 \mathrm{ng} / \mathrm{ml}( \pm 29.47)$ $58.63 \mathrm{ng} / \mathrm{ml}( \pm 32.9)$ in women and $44.95 \mathrm{ng} / \mathrm{ml}( \pm 27.56)$ in men, with no statistically significant differences found when HIV infected women were compared with those of the Camargo cohort, $(47,7 \pm 19,9 \mathrm{ng} / \mathrm{ml})(\mathrm{p}=0.06)$, although a trend towards higher levels in HIV infected women was observed.

Conclusions: In the present study no correlation between P1NP and b-CTX levels in HIV infected patients and incidence of vertebral fracture was found.

P1NP and b-CTX mean values in HIV infected women in our study are higher than those of healthy postmenopausal Spanish women, which means a higher bone turnover in this population. More studies are needed to clarify the extent and clinical impact of this finding.

Disclosure of Interest: None declared

DOI: 10.1136/annrheumdis-2018-eular.5853

\section{AB0993 PAIN RELIEF MANAGEMENT OF ACUTE OSTEOPOROTIC VERTEBRAL FRACTURE IN A REAL LIFE STUDY}

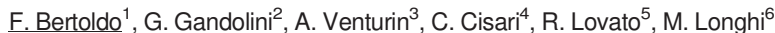
S. Farina ${ }^{7}$, E. Bertoldo ${ }^{8}$, R. Nuti ${ }^{9}$, on behalf of Servatius GISMO study group. ${ }^{1}$ Internal Medicine, University of Verona, Verona; ${ }^{2}$ rheumatology, IRCCS Don Gnocchi, Milan; ${ }^{3}$ Rheabiltation Unit, University of Padua, Padua; ${ }^{4}$ Orthopedic Unit, University of PO, Novara; ${ }^{5}$ Internal Medicine, Villa Berica Hospital, Vicenza; ${ }^{6}$ Orthopedic Unit, Galeazzi Institute, Mllan; ${ }^{7}$ Rheabiltation Unit, Crema Hospital, Crema; ${ }^{8}$ Rheumatology Unit, University of Verona, Verona; ${ }^{9}$ Internal Medicine, University of Siena, Siena, Italy

Background: Among all osteoporotic fractures the painful vertebral fractures (PVF) are the minority and their management is challenging for the clinician because the evidences about the best approach are conflicting and of low quality. Moreover there are no guidelines or consensus of experts. A real life picture of the management of the PVF is lacking in the literature.

Objectives: The primary end point of the study is to describe the pharmacological and or non-pharmacological management of PVF through the record of use of individual classes, associations and sequences of drugs or procedures. Secondary end point is the outcome of treatment in term of pain, disabilities and quality of life.

Methods: We present the iterim analysis results of a multicentric cross-sectional observational study. 400 interviews will be collected consecutively about pain, disability, pharmacological, spinal orthoses and orthopaedic surgery after the diagnosis of PFV in postmenopausal women treated by orthopaedics, endocrinologists, geriatricians, physiatrists, neurosurgeons and E.R. pysicians Pain and disability were quantified by NRS scale and by QUALEFFO-41. Data collected from the first 100 patients have been analysed.

Results: One hundred postmenopausal women aged $73.1 \pm 7.49$ y.o (age of menopause $48.6 \pm 3.9$ years, L1-L4 T-score $-2.75 \pm 0.92$, Total hip T-score -2.35 \pm 0.98 ) with a new or first PFV were recorded. About $49 \%$ of them had a previous vertebral fracture and $22 \%$ a previous non-vertebral fragility fracture, $27 \%$ was not on osteoporosis treatment. The interviews were collected $135 \pm 114$ days from diagnosis of $P V, 174 \pm 141$ days from onset of pain. $92.3 \% \pm 12 \%$ of subjects were treated for pain relief for a mean time of $98 \pm 12$ days. Only $1.6 \%$ of cohort 